\title{
INSPIREE:
}

\section{Kondisi Fisik Power Otot Tungkai dalam Kemampuan Smash Kedeng pada Permainan Sepak Takraw}

d.

https://doi.org/10.53905/inspiree.v1i3.21

*Jufrianis

${ }^{7}$ Program Studi Pendidikan Jasmani, Kesehatan dan Rekreasi, Universitas Pahlawan Tuanku Tambusai, Riau, Indonesia.

\begin{abstract}
Tujuan Penelitian. Tujuan dari penelitian ini adalah untuk mengetahui hubungan dari power otot tungkai dengan kemampuan smash kedeng.

Metode Penelitian. Penelitian ini dilakukan pada atlit Persatua Sepak Takraw Indonesia di Unit Kegiatan Mahasiswa Universitas Pahlawan Tuanku Tambusai Riau, Indonesia. Penelitian ini menggunakan metode deskriptif dengan pendekatan korelasional. Sampel terdiri dari 30 orang. Sebelum melakukan penelitian terlebih dahulu dilakukan uji coba terhadap instrumen tes yang akan digunakan dalam penelitian. Uji coba ini dimaksudkan untuk mengetahui apakah instrumen yang akan diuji valid dan reliabel. Teknik analisis data adalah uji normalitas, uji homogenitas dan uji linearitas

Hasil. Hasil penelitian ini menunjukkan bahwa (1) terdapat hubungan yang positif antara power otot tungkai dengan smash kedeng atas koefisien rx1y $=0,386$ dan memberikan pengaruh sebesar $14 \%$.

Kesimpulan. Berdasarkan hasil penelitian terdapat hubungan yang positif kondisi fisik power otot tungkai dalam kemampuan smash kedeng pada permainan sepak takraw.
\end{abstract}

Kata Kunci: power otot tungkai; kemampuan smash kedeng takraw.

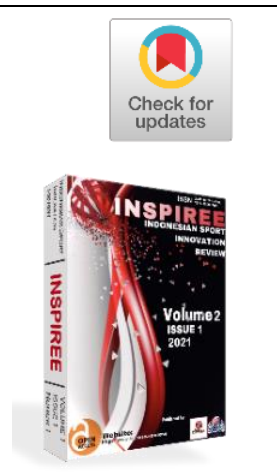

Published:

September 27, 2020

PENDAHULUAN

Sepak takraw sebagai suatu permainan yang didominasi kaki yang memainkan bola takraw diatas lapangan seluas lapangan bulu tangkis dan dipertandingkan antara dua regu yang saling berhadapan dengan jumlah pemain masing-masing 3 (tiga) orang (Achmad Sofyan Hanif, 2015). Di tengahnya dibatasi oleh jaring, dalam permainan sama seperti pemainan sepak bola, yang digunakan kaki dan semua anggota badan kecuali tangan. Tujuan dari permainan sepak takraw adalah mengembalikan bola sedemikian rupa sehingga dapat jatuh dilapangan lawan atau menyebabkan lawan membuat kesalahan atau pelanggaran (lyakrus, 2010).

Penguasaan keterampilan sepak takraw dapat berupa keterampilan individu dan keterampilan tim. Salah satu teknik dasar yang yang harus dikuasai dalam permainan sepak takraw adalah smash. Smash dalam permainan sepak takraw sangat dominan 
sekali untuk menghasilkan angka. Ada beberapa macam smash dalam permainan sepak takraw, antara lain: smash gulung (salto), smash kedeng, smash gunting, smash telapak kaki. Dalam penelitian ini akan dibahas lebih lanjut mengenai smash kedeng. Smash adalah suatu gerakan yang dinamis dan kompleks untuk memperoleh angka dalam permainan sepak takraw. Dalam melakukan smash dibutuhkan kemampuan fisik untuk melompat agar kemampuan smash dapat memperoleh hasil yang baik, terutama pada smash kedeng. Untuk menghasilkan smash yang baik diperlukan teknik smash yang akurat dan tepat, sehingga bola yang di smash akan sulit untuk dibendung dan diantisipasi oleh lawan. Sama halnya dalam melakukan smash kedeng agar dapat melompat dan menghasilkan sepakan yang keras dan akurat harus memiliki power tungkai yang kuat.

Smash merupakan upaya seorang pemain dalam melakukan serangan ke daerah lawan (Achmad Sofyan Hanif dan Asry Syam, 2015). Smash yang baik dan bagus akan mematikan bola di daerah lawan dan sulit bagi lawan untuk melakukan bendungan/mempertahankan daerahnya dari serangan (smash). Salah satu smash yang sering digunakan adalah smash kedeng. Smash kedeng merupakan jenis smash yang sering dilakukan pada pemain sepak takraw guna memberikan serangan pada pihak lawan (Zalfendi, 2009). Smash kedeng adalah jenis smash dalam sepak takraw yang dilakukan dengan kaki dan posisi awal bola berada di atas bagian samping depan pemain. Mulia P, 2010).

Istilah smash kedeng dalam bahasa inggrisnya yaitu spike sun back. Istilah spike sun back banyak digunakan orang laos yang bermukimdi Amerika dan Kanada, baik yang belajar di Laos maupun saat pengungsian. Menurut Rick Engel, spike sun back tepat jika dipelajari setelah berlatih spike kepala dan spike telapak kaki karena spike ini dilakukan dengan membelakangi net, melompat dan menendang bola dengan badan diatas net. Spike ini juga membutuhkan latihan dan timing yang tepatuntuk melompat dan menempatkan badan sesuai dengan posisi bola (Rick Engel, 2008). Smash kedeng merupakan smash yang biasanya bola dipukul dengan punggung kaki atau kaki bagian luar. Menurut lyakrus (2010), smash kedeng dilakukan dengan tumpuan salah satu kaki dengan membelakangi net kemudian menyepak bola dengan tungkai diangkat keatas diiringi dengan memutar badan kearah dalam. Smash kedeng permainan sepak takraw 
merupakan salah satu teknik dasar dan cara yang efektif untuk mendapatkan poin/angka. Kemampuan smash kedeng merupakan keterampilan yang tidak mudah, sebab kemampuan smash kedeng memiliki tingkat kesulitan yang cukup tinggi. Teknik melakukan smash kedeng menurut Wichai, Watana, Piyasak, "Turn your back to the opponent and strike the ball after it is reposition by feeder. Jump up using the standing leg and bend the knee of striking leg. Stretch the foot and strike the ball hard by using the lower toes and ankleto control the ball at the target direction." Gerakan smash kedeng merupakan suatu gerakan yang kompleks atau suatu serangkaian gerakan yang serentak tidak terputus dan disertai dengan tenaga yang besar. Pada perkembangannya smash kedeng juga dapat dilakukan dengan roll 360 derajat. Tentunya dengan tingkat kesukaran yang lebih tinggi akan tetapi mengalami kesulitan saat mendarat. Berdasarkan pendapat di atas, dapat diartikan yang dimaksud dengan smash kedeng adalah suatu pola gerak dalam permainan sepak takraw yang bertujuan untuk memberikan tekanan terhadap lawan, melalui pukulan dengan punggung kaki bagian luar ke arah daerah pertahanan lawan.

Dalam pelaksanan sash kedeng tidak terlepas pada kondisi fisik atlet daya ledak otot (Power) tungkai. Power atau daya ledak disebut juga sebagai kekuatan eksplosif yang mencangkup kekuatan dan kecepatan yang dinamis Ismaryati, 2011). Power merupakan komponen yang sangat diperlukan oleh setiap individu terutama olahragawan yang berkaitan dengan kerja fisik. Power identik dengan daya ledak kualitas yang memungkinkan otot atau sekelompok otot untuk menghasilkan kerja fisik secara eksplosif. Unsur penentu power adalah kekuatan otot, kecepatan rangsang syaraf dan kecepatan kontraksi otot. Power atau daya eksplosif power merupakan suatu rangkaian kerja beberapa unsur gerak otot dan menghasilkan daya ledak jika dua kekuatan tersebut bekerja secara bersamaan Sukirno, 2011) Menurut Tudor O. Bompa (2009) Daya Ledak adalah penghasil dalam tipe peregangan-penyusutan dari kontraksi.

Saat melakukan smash kedeng kekuatan diperoleh dari kecepatan otot tungkai atas / paha dan otot tungkai bawah berkontraksi dengan cepat. Jadi Power otot tungkai adalah kemampuan otot tungkai pada saat melakukan kontraksi sehingga mengasilkan kekuatan dan kecepatan yang baik. Adanya power otot tungkai yang baik 
tentunya tungkai dapat menjangkau bola yang dilambungkan dan dapat menyepak bola / smash dengan akurat dan melewati net.

\section{METODOLOGI PENELITIAN}

\section{Populasi dan Sampel}

Adapun populasi dari penelitian ini adalah seluruh atlit pemula PSTI Unit Kegiatan Mahasiswa (UKM) Universitas Pahlawan Tuanku Tambusai, Riau, Indonesia. Dalam penelitian ini adalah seluruh atlit pemula PSTI UKM Universitas yang berjumlah 30 orang.

\section{Rancangan Penelitian}

Penelitian ini bertujuan untuk mengetahui sejauh mana hubungan antara kondisi fisik power otot tungkai keseimbangan dengan kemampuan smash kedeng pada permainan sepak takraw. Oleh karena itu, riset komparasi sebab-akibat mencari perbedaan sedangkan riset korelasi mencari hubungan. Rancangan penelitian yang digunakan adalah desain korelasional (Correlational Design). Hal ini hanya melakukan satu kali pada masing-masing variabel yang terdiri dari variabel bebas $\left(\mathrm{X}_{1}\right)$ yaitu power otot tungkai dan variabel terikat $(\mathrm{Y})$, yaitu kemampuan smash kedeng pada permainan sepak takraw.

\section{Prosedur Tes dan Pengukuran}

Sebuah penelitian, peneliti harus memahami kriteria data yang baik dan mampu menentukan teknik yang tepat dalam mengumpulkan data. Jika tidak maka data yang dikumpulkan tidak akan diperoleh secara sempurna. Adapun metode pengumpulan data dalam penelitian ini adalah metode test. Dalam penelitian ini ada 2 macam test, yaitu dengan tes pengukuran power otot tungkai dan tes smash kedeng takraw.

\section{Analisis Statistik}

Teknik Korelasi ini digunakan untuk melihat hubungan masing masing variabel power otot tungkai $\left(\mathrm{X}_{1}\right)$ dengan kemampuan smash kedeng $(\mathrm{Y})$. Analisis pearson product moment correlation akan digunakan pada uji ini. Hipotesis statistic yang digunakan dalam penellitian ini adalah sebagai berikut:

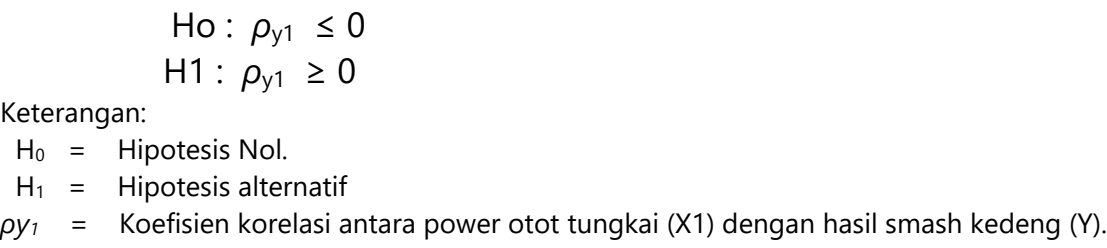




\section{HASIL PENELITIAN}

Deskripsi hasil penelitian dianalisis berupa gambaran umum masing masing variabel yang di teliti, yaitu Hasil smash kedeng $(\mathrm{Y})$, Power otot tungkai (X1), Kelentukan tungkai (X2), dan Keseimbangan (X3) dengan jumlah sampel sebanyak 30 orang. Gambaran umum yang disajikan dalam hal ini mencakup rerata, modus, median, variansi dan simpangan baku, serta distribusi frekuensi dengan di sertai histogram, Beriku ini secara berturut-turut data masing masing variabel dideskripsikan sebagai berikut:

Tabel 1. Simpulan Rerata, SD, Modus, Median, Range, dan Varians

\begin{tabular}{|c|c|c|c|}
\hline \multicolumn{4}{|c|}{ Statistics } \\
\hline \multirow{3}{*}{$\mathbf{N}$} & \multicolumn{2}{|c|}{ Smash_kedeng } & \multirow[t]{2}{*}{ Power_otot_tungka } \\
\hline & Valid & 30 & \\
\hline & Missing & 30 & 30 \\
\hline Mean & 5,00 & & 41,93 \\
\hline Std. Error of Mean &, 505 & & 2,115 \\
\hline Median & 5,00 & & 43,00 \\
\hline Mode & 7 & & 28 \\
\hline Std. Deviation & 2,767 & & 11,585 \\
\hline Variance & 7,655 & & 134,202 \\
\hline Range & 10 & & 34 \\
\hline Minimum & 0 & & 26 \\
\hline Maximum & 10 & & 60 \\
\hline Sum & 150 & & 1258 \\
\hline
\end{tabular}

Pengujian normalitas dilakukan pada variabel terikat yaitu smash kedeng $(\mathrm{Y})$, power otot tungkai $\left(\mathrm{X}_{1}\right)$ :

\section{Uji Normalitas}

Uji normalitas data dilakukan dengan menggunakan teknik. Kolmogorov-Smirnov Test. Data akan dinyatakan normal apabila signifikansi perhitungan normalitas $>0.05$ $\left(\mathrm{H}_{1}\right)$, dan apabila hasil perhitungan dibawah 0.05 maka data dinyatakan tidak normal $\left(\mathrm{H}_{0}\right)$. Dari hasil perhitungan dapat diketuhi bahwa semua nilai signifikansi keempat variabel berada diatas 0.05 . Seperti yang disajikan pada tampilan data dibawah ini:

\begin{tabular}{|c|c|c|c|c|c|}
\hline No & Variabel & $\mathbf{N}$ & L-hitung & L-tabel & Keterangan \\
\hline 1 & $Y$ & 30 & 0.194 & 0.05 & Normal \\
\hline 2 & $X_{1}$ & 30 & 0.156 & 0.05 & Normal \\
\hline
\end{tabular}

Nilai signifikansi kolmogorov-Smirnoz pada variabel smash kedeng sebesar 0,194, pada variabel power otot tungkai sebesar 0,156.

\section{Uji Homogenitas}

Uji Homogenitas digunakan untuk mengetahui varian dari beberapa populasi sama atau tidak. Uji ini biasanya dilakukan sebagai prasyarat dalam analisis Independen 
sampai T Tes dan Anoa. Asumsi yang mendasar dalam analisis of varians (ANOVA) adalah bahwa varian dari populasi adalah sama. Uji homogenitas digunakan sebagai bahan acuan untuk menentukan keputusan uji statistic. Adapun dasar pengambilan keputusan dalam uji homogenitas adalah jika nilai signifikansi $<0,05$ maka dikatakan bahwa varian dari dua atau lebih kelompok populasi data adalah tidak sama. Jika nilai signifikansi > 0,05 maka dikatakan bahwa varian dari dua atau lebih kelompok populasi data sama.

Tabel 3. Hasil Uji Homogenitas

\begin{tabular}{ccccc}
\hline No & Variabel $X$ & Variabel $Y$ & Sig $>0,05$ & Kesimpulan \\
\hline 1 & Power Otot Tungkai & Smash Kedeng & 0.243 & Homogen
\end{tabular}

Berdasarkan tabel diatas dapat dilihat bahwa ketiga variabel $\mathrm{X}$ mempunyai signifikan lebih besar dari 0,05. Itu artinya bahwa data populasi penelitian mempunyai varian populasi yang sama.

\section{Uji Hipotesis Penelitian}

Hipotesis pertama dalam penelitian ini adalah apakah terdapat hubungan positif antara power otot tungkai dengan smash kedeng atau tidak. Berdasarkan hasil perhitungan atau derajat hubungan antara power otot tungkai dengan smash kedeng diperoleh nilai korelasi $r_{x 1 y}=0.386$ dengan sig $\alpha=0.35$. Uji signifikasi korelasi ini disajikan dalam bentuk tabel berikut:

\begin{tabular}{ccccc} 
& \multicolumn{4}{c}{ Tabel 4. Korelasi sederhana $Y$ atas $X_{1}$} \\
\hline $\mathbf{N}$ & Nilai Korelasi & Signifikansi Perhitungan & $\begin{array}{c}\text { Signifikansi } \\
\text { Tabel }\end{array}$ & Keterangan \\
\hline 30 & 0.386 & 0.035 & 0.05 & Berkorelasi Positif \\
\hline
\end{tabular}

Berdasarkan hasil korelasi sederhana diperoleh nilai korelasi 0.386 pada $p \leq 0,05$, sehingga $\mathrm{HO}$ ditolak dan $\mathrm{H} 1$ diterima sehingga dapat disimpulkan bahwa korelasi antara power otot tungkai dengan smash kedeng sebesar (r) 0,035 adalah signifikan. Nilai korelasi $(r)$ bertanda positif, dengan demikian korelasi antara variabel $\mathrm{X}_{1}$ terhadap Y adalah memiliki arah hubungan positif, berarti semakin tinggi power otot tungkai semakin baik pula kemampuan smash kedeng. Selain itu, korelasi ini berada di rentang 0,20-0,399 yang berarti memiliki hubungan yang tergolong rendah. Hal ini menunjukkan bahwa terjadi hubungan yang rendah positif dan signifikan antara power otot tungkai. Sedangkan hasil koefisien determinasi pada perhitungan regresi 
sederhana adalah $r^{2}=(0,386)^{2}=0,14$ atau $14 \%$. Uji regresi ini juga disajikan dalam bentuk tabel berikutT:

Tabel 5. Regresi sederhana $Y$ atas $X_{1}$

\begin{tabular}{lrrrr}
\hline \multicolumn{6}{c}{ Model Summary } \\
\hline Model & R & R Square & Adjusted R Square & Std. Error of the Estimate \\
\hline 1 &, $386^{\text {a }}$ &, 149 & &, 119 \\
\hline a. Predictors: (Constant), power_otot_tungkai & & & 2,597 \\
\hline
\end{tabular}

Berarti bahwa 14\% varians yang menyebabkan terjadinya keberhasilan pada smash kedeng dapat dipengaruhi atau ditentukan oleh power otot tungkai.

\section{PEMBAHASAN}

Berdasarkan hasil pengujian hipotesis, ternyata ketiga hipotesis yang di ajukan secara signifikansi dapat diterima. Uraian masing masing penerimaan ketiha hipotesis yang dimaksud dapat dijelaskan sebagai berikut. Pertama, pengujian hipotesis pertama menyimpulkan bahwa terdapat hubungan positif yang signifikan antara power otot tungkai dengan kemampuan smash kedeng yang di tunjukan oleh hasil analisis korelasi sederhana antara power otot tungkai dengan kemampuan smash kedeng diperoleh nilai r_x1y koefisien korelasi sebesar 0.386 dengan kontribusi atau 14\%. Nilai ini memberikan pengertian bahwa keterkaitan antara power otot tungkai dengan kemampuan smash kedeng adalah signifikan atau positif, artinya semakin tinggi power otot tungkai akan di ikuti dengan naiknya kemampuan smash kedeng.

\section{KESIMPULAN}

Berdasarkan hasil pengolahan dan analisis data mengenai korelasi power otot tungkai, kelentukan tungkai dan keseimbangan dengan kemampuan smash kedeng, dapat ditarik kesimpulan bahwa hasil pengujian hipotesis yang menyatakan bahwa terdapat hubungan yang positif antara power otot tungkai dengan kemampuan smash kedeng. Peneliti memiliki pandangan bahwa setiap peningkatan kemampuan kondisi fisik khususnya power otot tungkai bertujuan untuk meningkatkan kemampuan gerak dalam berolahraga yang telah dimiliki menjadi lebih baik termasuk kemampuan smash kedeng pada permainan sepak takraw. Masih banyak faktor lain yang turut menjadi penentu kemampuan smash kedeng seperti tekanan, kondisi fisik, kepercayaan diri, mental bertanding dan faktor lainnya termasuk faktor yang bersifat psikologis seperti motivasi latihan. 


\section{DAFTAR PUSTAKA}

Ade Prasetyo, K. ., \& Henjilito, R. (2020). Ketepatan Shooting Sepakbola Pada Siswa Sma Melihat Dari Kontribusi Daya Ledak Otot Tungkai. INSPIREE: Indonesian Sport Innovation Review, 1(2), 66-74. https://doi.org/10.53905/inspiree.v1i2.8

Adi Saputra, S. (2020). Giakusuki Pada Karate: Analisis Peran Kekuatan Otot Lengan Dan Otot Bahu: Giakusuki On Karate: Analysis Of The Role Of Arm Strength And Shoulder Muscles. INSPIREE: Indonesian Sport Innovation Review, 1(1), 24-35. https://doi.org/10.53905/inspiree.v1i1.5

Ahmad Pratama, S. (2020). Perbandingan Ketepatan Menendang Kearah Gawang: KuraKura (Dalam Vs Luar): Comparison Of Accuracy Shooting: Turtle Technique Analysis (Inside Vs Outside). INSPIREE: Indonesian Sport Innovation Review, 1(1), 36-44. https://doi.org/10.53905/inspiree.v1i1.3

Hanif, Achmad Sofyan. Kepelatihan Sepak Takraw. Jakarta : PT RajaGrafindo Persada, 2015.

Hanif, Achmad Sofyan. Asry Syam. Sepak Takraw Pantai. Jakarta: PT. RajaGrafindo Persada, 2015.

Ismaryati. Tes \& Pengukuran Olahraga. Surakarta: Lembaga Pengembangan Pendidikan (LPP) UNS dan UPT Penerbitan dan Percetakan UNS (UNS Press), 2011. Iqbal, M. (2020). The Limb Explosive Power and Goal Target Accuracy on Futsal Playing Skills: Correlational Analysis Study: Poweri Otot Tungkai dan Akurasi Sasaran dalam Keterampilan Bermain Futsal: Studi Analisis Korelasional. INSPIREE: Indonesian Sport Innovation Review, 1(1), 1-8.

\section{https://doi.org/10.53905/inspiree.v1i1.1}

lyakrus, Permainan Sepak Takraw. Palembang: Universitas Sriwijaya, 2010.

Mulia P, Asyiknya Berolahraga Sepak Takraw. Makassar: CV Upaya Peraga Gading, 2010. Sukirno, Dasar-Dasar Atletik dan Latihan Fisik. Palembang: Dramata, 2011.

Tudor O. Bompa, Periodization, Theory and Methodologi Of Training. HK Rewards, 2009.

Zalfendi, Permainan Sepak Takraw. Padang: Sukabina Press, 2009. 


\section{LAMPIRAN}

\section{Informasi Tentang Penulis:}

Dr. Jufrianis, M.Pd:

Email: jufrianis93@gmail.com; Orchid Id:0000-0002-5526-296X; Scopus Author ID: 57214082557; Phone Number: +6282169552652; Program Studi Pendidikan Jasmani, Kesehatan dan Rekreasi, Universitas Pahlawan Tuanku Tambusai, Riau, Indonesia; Alamat: Jln. Tuanku Tambsuai, No.23, Bangkinang Kota, 28412, Indonesia. 